\title{
29. DOWNHOLE MEASUREMENTS AND ELECTRICAL IMAGES IN HOLE 896A, COSTA RICA RIFT ${ }^{1}$
}

\author{
François Dominique de Larouzière, ${ }^{2}$ Philippe A. Pezard, ${ }^{2,3}$ Mariem Ayadi, ${ }^{2,3}$ and Keir Becker ${ }^{4}$
}

\begin{abstract}
A complete set of downhole measurements along with Formation MicroScanner (FMS) electrical images of the borehole surface was recorded in the basement of Hole 896A during Ocean Drilling Program Leg 148. This complete geophysical data set offers, largely because of the quality of the recorded data, the first opportunity to integrate core results, meter-scale logs, and centimeter-scale borehole wall images in a structural sense for oceanic basement. At an even larger scale, extremely low resistivity values and consistently high acoustic velocity were measured in the hole. These values indicate that the basement has been altered to a large extent at this topographic high and heat-flow maximum, but also that cracks and fractures once conveying fluid to alter fresh basalts are now sealed.

Nearly 7700 features were mapped over $225 \mathrm{~m}$ of images ( 34.3 per meter on average) and described in terms of geometry and aperture. The penetrated basement section consequently appears to be intensively fractured. In the laboratory, Archie's formula (1942) is found to provide a reasonable first-order estimate of porosity for this severely fractured basement section. Once applied to downhole measurements at meter-scale, this relationship yields a continuous porosity profile through the penetrated section. The combination of meter-scale (with the Dual LateroLog) and centimeter-scale (with FMS images) investigations of the rock structure outlines the presence of four narrow and subvertical fracture zones in the analyzed interval.

At $356 \mathrm{mbsf}$, one of these narrow intervals appears to separate two different fracture sets, as well as stress regimes in terms of borehole shape and rupture mode. This might indicate the presence of a presently active fault zone at this depth, which divides the upper basement and may explain the surprisingly high permeability values inferred deeper in the hole from packer experiments. Borehole elongations are very small throughout, but coherent in azimuth and distribution with those obtained only $1 \mathrm{~km}$ away at Site 504. In the near future, a detailed description of upper basement structures both in terms of geometry and volume should arise from the combined analysis of standard downhole measurements and fracture sets obtained from FMS image analysis.
\end{abstract}

\section{INTRODUCTION}

The main objective of Ocean Drilling Program Leg 148 was to deepen Hole 504B through the dike/gabbro transitions. As a result of drilling problems in this deep hole, alternative work was conducted nearby in Hole $896 \mathrm{~A}$, in which 8 days were devoted to coring and 3 days to logging operations. Site 896 was selected because it lies on a topographic high that corresponds to a local heat-flow maximum. A major objective of drilling was to study the local variability of the accretion process, for example, by attempting to correlate structural and volcanic features found in Hole 896A (massive flows) to those found in Hole 504B.

Site 896 is located $1 \mathrm{~km}$ to the southeast of Site 504, in the eastern equatorial Pacific Ocean. Like Hole 504B, Hole 896A penetrates 5.9m.y.-old crust about $200 \mathrm{~km}$ south of the Costa Rica Rift, the easternmost segment of three forming the Galapagos or "Cocos-Nazca" spreading center. The Costa Rica Rift spreads asymmetrically at an intermediate rate (a half-rate of $3.6 \mathrm{~cm} / \mathrm{yr}$ to the south and $3.0 \mathrm{~cm} / \mathrm{yr}$ to the north; Hey et al., 1977). The basement relief, south of Costa

'Alt, J.C., Kinoshita, H., Stokking, L.B., and Michael, P.J. (Eds.), 1996. Proc. ODP, Sci. Results, 148: College Station, TX (Ocean Drilling Program).

${ }^{2}$ Laboratoire de Mesures en Forage, Institut Méditerranéen de Technologie, Technopôle de Château-Gombert, F-13451 Marseille Cedex 20, France. de Larouzière: fdl@imtmer1.imt-mrs.fr; Pezard: pezard@imtmerl.imt-mrs.fr; Ayadi: ayadi@imtmer1. imt-mrs.fr

'Laboratoire de Pétrologie Magmatique, URA CNRS 1277, Faculté des Sciences et Techniques de Saint-Jérôme, Avenue Escadrille Normandie-Niemen, F-13397 Marseille Cedex 20, France.

${ }^{4}$ Division of Marine Geology and Geophysics, Rosenstiel School of Marine and Atmospheric Science, 4600 Rickenbacker Causeway, University of Miami, Miami, FL 33149-1098, U.S.A. kbecker@rsmas.miami.edu
Rica Rift (Nazca Plate), results from the presence of east-west normal faults parallel to the rift axis, which produce north-dipping half-graben structures with blocks tilted less than $5^{\circ}$, separated by ridges 1 to $2 \mathrm{~km}$ wide (Langseth et al., 1988). Site 896 is located in $3439.8 \mathrm{~m}$ of water, at the center of a spreading segment. This location is significant in terms of magmatic and tectonic processes that once constituted the site, which also affect locally hydrothermal alteration processes and the physical structure of the investigated crust.

In Hole $896 \mathrm{~A}$, basement was first encountered at $179.0 \mathrm{mbsf}$, and was cored from $195.1 \mathrm{mbsf}$ to $469.0 \mathrm{mbsf}$. Mainly pillow basalts $(57 \%)$, minor massive flows $(38 \%)$, and breccias ( $5 \%$ : hyaloclastites, and/or shards of altered glass or vitreous basalt fragments included in carbonate- and clay-rich matrix) were recovered in 30 cores for an average recovery of $27.7 \%$. Two steeply dipping $\left(74^{\circ}-78^{\circ}\right)$ dikes were found in the hole. All of the rocks observed have been slightly altered at low temperature. In comparison with the extrusive section of Hole 504B, the section from Hole 896A contains more massive units and brecciated levels, and fewer pillow units (Alt, Kinoshita, Stokking, et al., 1993).

\section{Logging Operations}

Two phases of logging were conducted in Hole 896A. During the first phase, the induced geochemical combination (GLT), naturalgamma spectroscopy tool (NGT), and temperature logging tool (TLT) were run. The second phase consisted first of a logging string containing the dual laterolog electrical resistivity tool (DLL), the sonic density tool (SDT) and the NGT. A packer experiment was conducted next, and the triaxial magnetometer was then run. Finally, two passes of the Formation MicroScanner (FMS, Schlumberger ${ }^{\mathrm{TM}}$ ) electrical imaging tool were recorded. During this final phase, an obstruc- 


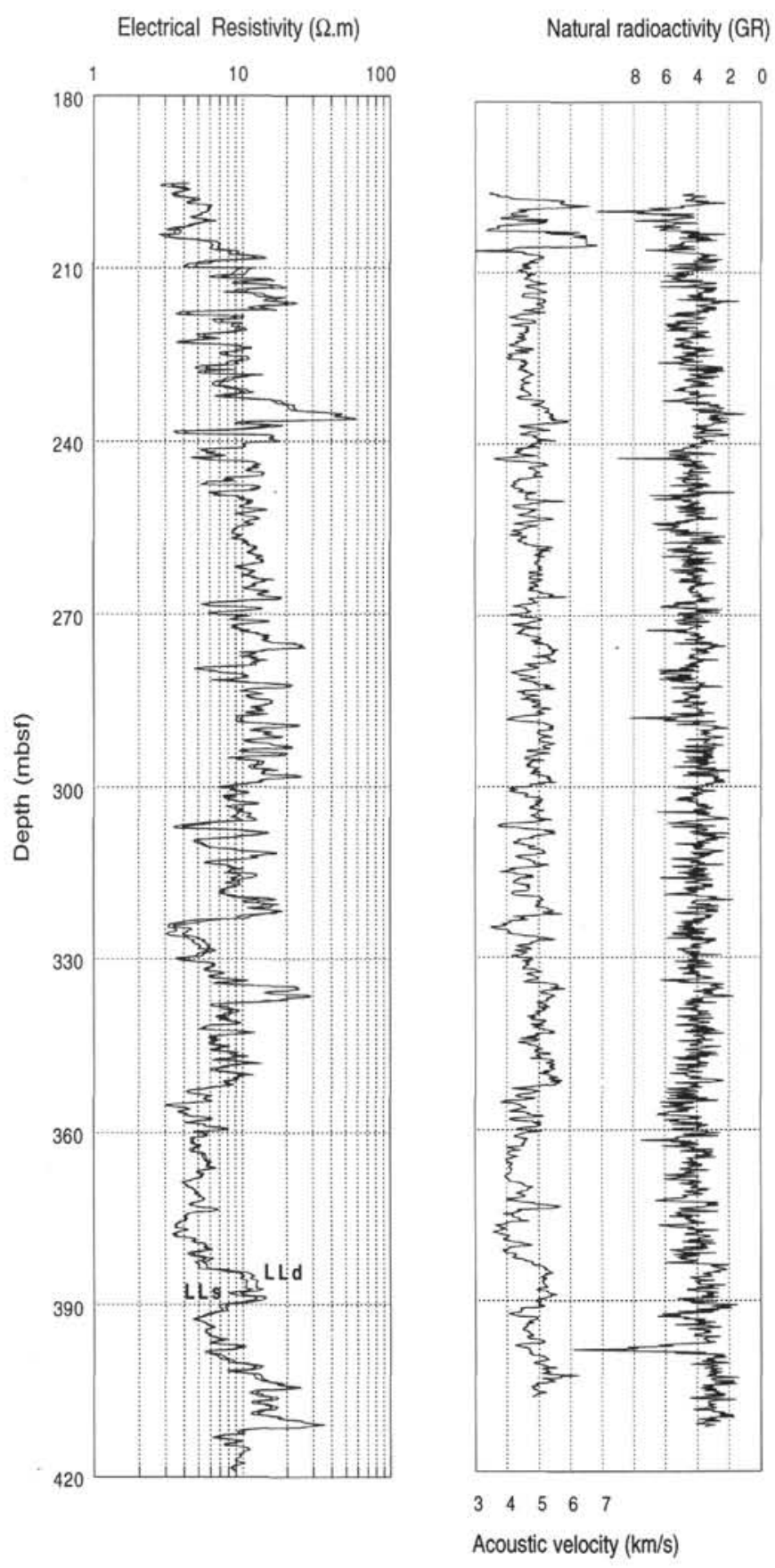

Figure 1. Electrical resistivity $(\Omega \mathrm{m})$ measurements, acoustic velocity $(\mathrm{km} / \mathrm{s})$ and natural radioactivity (Gapi) recorded in Hole 896A. Depths are in meters below seafloor (mbsf)

tion was encountered at $423 \mathrm{mbsf}$, so the deepest $46 \mathrm{~m}$ of the hole could not be logged.

Geophysical measurements are of excellent quality (Fig. 1), with high electrical resistivity and acoustic velocity values outlining the presence of flows as in Hole 504B (Pezard, 1990). The natural radioactivity is generally low, with minimum values in the flows and a few meter-scale peaks in zones of low electrical resistivity and acoustic velocity. The first results of downhole measurements and image analysis are presented here in terms of aperture of the fractures, hence, porosity, geometry of the fracture network, and relationship to the present stress field.

\section{PHYSICAL PROPERTIES}

Unlike bulk density, acoustic velocity, or electrical resistivity, the porosity of sedimentary rocks is not directly and continuously measurable in situ with geophysical logs at present. However, measurements of cores give local values of such a parameter. Measurements of wet-bulk density, compressional-wave velocity $\left(V_{p}\right)$, thermal conductivity, and electrical resistivity were made on selected water-saturated samples from Hole 896A. Porosities and grain densities were computed for the same samples from the difference between wet and dry weight, and formation factors were obtained from measurements of electrical resistivity, assuming a pore-fluid seawater resistivity of $0.20 \Omega \mathrm{m}$ at $25^{\circ} \mathrm{C}$. The measurements generally agree with log data and indicate that the recovered basalts are altered. This is supported by the measured electrical resistivity, with values generally less than $10.0 \Omega \mathrm{m}$. This value was found to be characteristic of altered pillows in Hole 504B (Pezard, 1990). Also, the acoustic velocity is almost greater than $4.0 \mathrm{~km} / \mathrm{s}$ throughout in Hole $896 \mathrm{~A}$, which supports the idea of pervasive pore space filling by secondary minerals. On the other hand, Moos et al. (1990), for example, reported numerous sections with values less than $3.5 \mathrm{~km} / \mathrm{s}$ in the shallow basement of Hole 504B. Physical property measurements in Hole 896A consequently indicate that the shallow crust at Site 896 has been altered to a large extent by hydrothermal circulation.

\section{Acoustic Velocity and Porosity}

Measured compressional velocities average $5.7 \mathrm{~km} / \mathrm{s}$ in the laboratory, whereas the porosities generally range from $2 \%$ to $10 \%$, although a few brecciated samples gave values as high as $17 \%$ (Fig. 2). A linear regression between porosity and acoustic velocity may be derived at centimeter-scale from core data, eventually allowing one to derive a meter-scale porosity profile from downhole measurement of acoustic velocity.

\section{Formation Factor and Porosity}

Electrical measurements on core at room temperature and atmospheric pressure show no particular trend with depth (Alt, Kinoshita, Stokking, et al., 1993), but correlate well with measured porosities (Fig. 2). The resistivity of a saturated rock depends on numerous factors (i.e., pore-space topology, such as geometry and connectivity of the pores, as well as distribution and nature of alteration products). Some of these factors are difficult to describe in a continuous fashion, and empirical formulae are often used to relate resistivity to porosity. Archie's formula (1942) has been considered often to provide a good first-order estimate for porosity of the oceanic crust (Becker, 1985). Pezard (1990) used a more precise, although less general, relationship valid only in the low porosity range $(<8 \%-10 \%)$. Formation factor (FF) and porosity $(\varnothing)$ were inversely related through a porevolume tortuosity factor $\left(\mathrm{T}_{\mathrm{v}}=10\right)$ such as $\mathrm{FF}=[10 / \varnothing]$.

In the present data set, such relationships with tortuosity values of 15 and 20 provide a good first-order representation at low porosity and at formation factors greater than 400 (Fig. 2). However, Archie's law appears to give a much better representation of the data less than 400 and may be considered for data greater than that. As formation factors greater than 300 generally were not recorded at meter-scale during downhole measurements in Hole 896A, Archie's formula was considered to provide a reasonable porosity estimate for basalts penetrated in Hole 896A (Fig. 3).

\section{DOWNHOLE MEASUREMENTS}

Rocks found in Hole 896A consist mainly of pillows and minor massive units interpreted as thin flows interbedded into the lithologic 
column. Alteration appears to be minimal in massive units (293.0 $298.0 \mathrm{mbsf}$ ), and also in a thick series of massive units (i.e., 385.0 391.0 and $415.0-414.0 \mathrm{mbsf}$ ). Sharp changes in acoustic velocity and electrical resistivity are obtained at $325.0,355.0$, and $385.0 \mathrm{mbsf}$ (Fig. 1), possibly outlining the presence of intensively fractured intervals.

\section{Electrical Resistivity}

Electrical resistivity data were recorded with a lateral device, the Dual Laterolog (DLL) tool of Schlumberger. Lateral devices are largely influenced by anisotropy and are accurate at high resistivity values (with an error less than $5.0 \%$ up to $40,000 \Omega \mathrm{m}$ for the DLL), such as those obtained in crystalline formations. The physical principle of the DLL is to measure an electrical potential modulated by variable current used to focus the measuring current in a $60-\mathrm{cm}$-thick cylindrical beam (Ellis, 1987). This current flows from a downhole electrode to a remote return, and the sensor is designed to provide two measurements of resistivity often referred to as deep (LLd) and shallow (LLs) because of their respective horizontal penetration into the rock.

Electrical resistivities recorded in Hole 896A with the DLL average $10.0 \Omega \mathrm{m}$ in the pillows and thin flows of the upper half of the hole, whereas, in the lower part, resistivities are found to be as low as $3.0 \Omega \mathrm{m}$ (Fig. 1), a value never reached using the same sensor in Hole 504B (Pezard, 1990). These low values probably reflect the extent of groundmass alteration and associated neoformation of conductive minerals in fracture and veins. Compressional velocities average 5.0 $\mathrm{km} / \mathrm{s}$ in the hole and are never less than $3.5 \mathrm{~km} / \mathrm{s}$, consequently higher than that obtained in the upper part of Hole 504B (Moos et al., 1990). This also reflects the importance of crack sealing at Hole $896 \mathrm{~A}$, in relation to intense hydrothermal circulation and alteration at this basement high and local heat-flow maximum.

\section{Porosity}

Two different estimates of porosity may be obtained from DLL data. The first one may be derived from the deep penetrating measurement (LLd), which is less sensitive to borehole effects than the shallow one (LLs). As such, it may be considered as representative of the total porosity of the rock when derived from Archie's formula (Archie, 1942; Brace et al., 1965; Becker, 1985), yielding then an estimate of "total porosity" referred to as $\emptyset_{\mathrm{A}}$ in the following, although the LLd is mostly sensitive to the horizontal resistivity of the rock formation and, hence, affected strongly when subhorizontal conductive fractures are encountered.

A second porosity estimate might be obtained from the difference between the two measurements (Pezard and Anderson, 1990). Because of the tool geometry and strong focusing, the presence of subhorizontal conductive features decreases the deep measurement more than the shallow one. In contrast, the deep resistivity measurement (LLd) always reads higher than the shallow one (LLs) in front of subvertical structures. This method consequently provides an estimate of porosity in strongly anisotropic media. This estimate is, however, a minimum one because of potential conflicting effects of both horizontal $\left(\emptyset_{\mathrm{h} \text {-DLL }}\right)$ and vertical $\left(\emptyset_{\mathrm{v}-\mathrm{DLL}}\right)$ structures that may cancel out to give a minimum value of, in this case, overall fracture porosity $\left(\varnothing_{\text {I-DLL }}\right)$.

In Hole $896 \mathrm{~A}, \varnothing_{\mathrm{h}-\mathrm{DLL}}$ and $\emptyset_{\mathrm{v}-\mathrm{DLL}}$ are in the $0.0 \%-0.5 \%$ porosity range, except for a few discrete zones (at 240.0, 307.0, and 323.0$332.0 \mathrm{mbsf}$ ) where vertical features reach values greater than $1.0 \%$ and as high as $3.5 \%$ (Fig. 4). These values are similar to those obtained at the same depth in Hole 504B (Pezard, 1990) and, aside from the three latter zones, do not show a large degree of organization of the fracturing in the penetrated sequence. Subhorizontal and subvertical structures are observed to alternate along the penetrated interval, although organizing vs. depth in tens-of-meter-long sections. Subver-
A
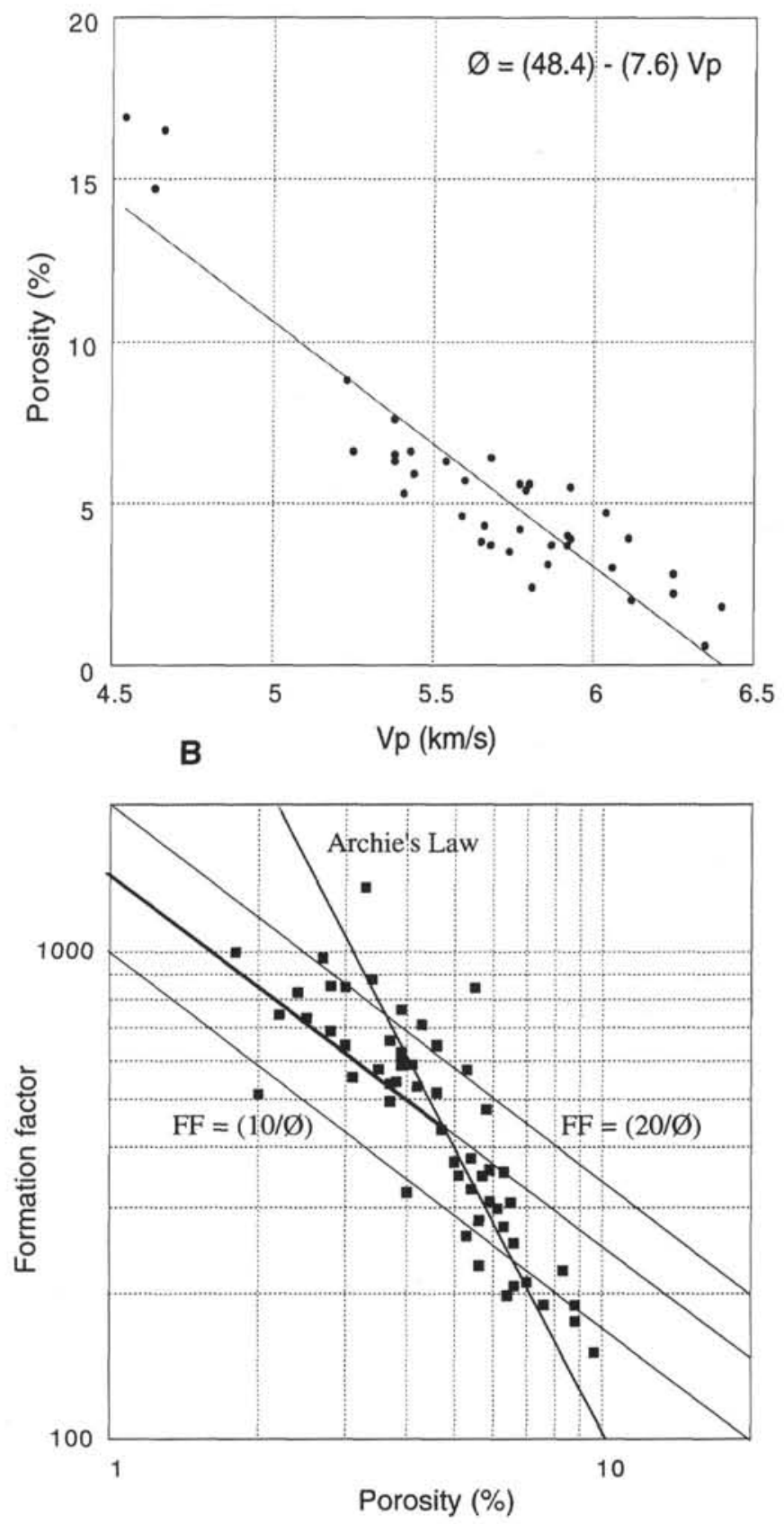

Figure 2. Porosity vs. acoustic velocity and formation factor of core samples from Hole 896A measured during the leg. A. The line corresponds to a bestfit regression to the data (with $R=0.92$ ). B. The lines represent Archie's law and models of high-aspect ratio porous media with $\mathrm{FF}=[10 / \varnothing], \mathrm{FF}=[15 / \varnothing]$, and $\mathrm{FF}=[20 / \varnothing]$. Although more accurate locally than the more general Archie's law, none appears to fit the entire data set.

tical structures dominate from 240.0 to $285.0 \mathrm{mbsf}$ and, below, in four narrow zones with apparent thicknesses in the hole from 5 to 10 $\mathrm{m}$, yielding meter-scale-wide features when accounting for dip, and average spacing in the hole of about $20 \mathrm{~m}$. The anticorrelation between porosity and compressional velocity (Fig. 4) is well expressed throughout, whereas fractured sections detected with the DLL are also that of high total porosity and low acoustic velocity. 
A
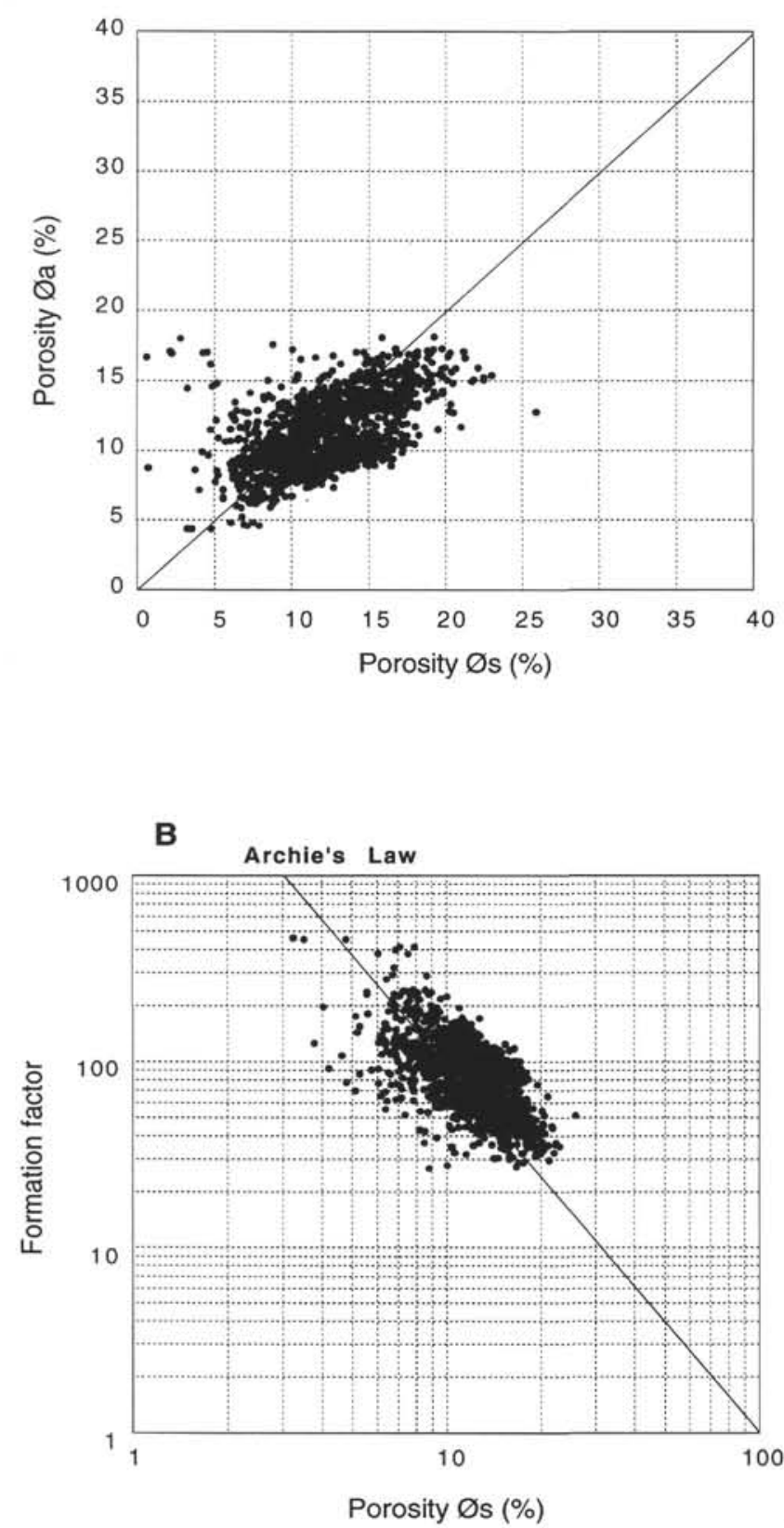

Figure 3. A. Total porosity $\left(\emptyset_{\mathrm{a}}\right)$ vs. porosity derived from acoustic velocity $\left(\emptyset_{x}\right)$. B. Formation factor vs. ( $\left.\varnothing_{*}\right)$ for downhole measurements in Hole 896A.

\section{FMS ELECTRICAL IMAGES}

The FMS creates a picture of the borehole wall by mapping electrical conductivity variations in the rock with an array of small, padmounted electrodes (Lüthi and Banavar, 1988). The slimhole configuration developed for ODP (Pezard et al., 1990) uses four pads, each with 16 buttons; a single pass of the tool maps about $22 \%$ of the 25.4 $\mathrm{cm}$-diameter borehole. Each electrode is oriented in space with sets of three-axis accelerometers and fluxgate magnetometers, making it possible to derive the strike and dip of geological structures. During logging, current flows from the lower section of the tool into the rock formation, then to a return electrode located at the top of the sonde.
A constant difference of electrical potential is held between each of the electrodes and the remote return. As the conductivity of the rock formation varies in front of each electrode during recording, a variable current is injected for each electrode into the rock to satisfy the constant potential condition.

Because of the electrode geometry, the tool has a moderately shallow depth of investigation (a few centimeters beyond the borehole wall). FMS data are recorded each $2.5 \mathrm{~mm}$, as the tool moves up the borehole; vertical resolution of individual features is about a centimeter. The tool can, however, detect thinner features (down to a few microns), provided they have sufficient resistivity contrast to the surrounding matrix. The images recorded with the FMS show conductivity changes caused by bed structures and boundaries, as well as by the presence of fractures, either open or mineralized. The conduction may be electrolytic for pore space open to fluid circulation, or surfacic with exchange of cations along pore surfaces for altered rocks.

Only 16 gray or color scales are traditionally represented in hard copies of the images, often yielding a somewhat degraded picture of the real data. As a consequence, these images should be exclusively investigated on a workstation capable of displaying the full breadth of the data set, for example by zooming in and out of the images interactively. Conductive events are normally reproduced with darker shades, and resistive ones in white. The images presented in this paper are, therefore, of lower apparent quality than those used to analyze the data set.

\section{Data Processing}

Data processing (using Logos ${ }^{\mathrm{TM}}$ software) is required to convert the raw data into a gray-scale (or color-scale) image representative of conductivity changes. Data processing includes conversion of raw data to variable-intensity gray or color images. As the supposed "constant" difference of potential is actually regulated during recording to adapt to rock resistivity in order to produce the best possible contrast, FMS images do not represent a direct map of electrical conductivity of the borehole wall. Such a map can be obtained only after calibration of the FMS images with calibrated electrical resistivity measurements with a similar depth of penetration into the rock, such as that of the shallow Laterolog (LLs). The button current is thus recorded as a curve representing relative changes in microresistivity caused by either (1) varying electrolytic conduction as a function of fluid type and temperature, or changes in grain and pore volume, size, and geometry, or (2) cation exchanges onto clay minerals surfaces. Initial FMS processing consequently consists of two main phases: data restoration and resistivity calibration from a standard resistivity (here the LLs).

\section{Image Analysis Software: FracView}

After processing and calibration, the images were analyzed with FracView, a Schlumberger interpretative software allowing for interactive display and interpretation of oriented images (Fig. 5). The possibility of adding tracks containing standard measurements, such as electrical resistivity from the DLL (Fig. 5), brings a large-scale perspective to the data set. Examples of images recorded in Hole 896A in a thin flow (Fig. 5) and in fractured pillows (Fig. 6) are presented.

\section{FMS Images Analysis}

\section{Fracture Identification and Methodology}

The fracture analysis method used in FracView was developed by Lüthi and Souhaité (1990), and, beyond detection and mapping, is aimed at providing a quantitative evaluation of "fracture aperture" from the calibrated electrical images. This evaluation is based on finite-element modeling of the theoretical response of the FMS in 
front of conductive anomalies such as fractures. Potential fractures are determined as locations where conductivity values exceed the local matrix conductivity by a statistically significant amount. Line sharpening and trace connectivity tests are performed to trace the fractures, and apertures are computed along each trace for all fracture locations.

After manual identification, fracture traces or contrasting features were classified for the purpose of the analysis in terms of horizontal (red), intermediate (green), and vertical (blue) fracture sets (Fig. 7). Then, these are converted to apparent electrical "apertures" with FracView considering each feature as filled with seawater of average conductivity equal to $10.0 \mathrm{~S} / \mathrm{m}$ over this upper basement section. The boundaries between the three sets were defined somewhat arbitrarily, but also with the goal of comparing the resulting "FMS fracture porosity profiles" to those derived using the DLL. A total of 7721 features were mapped from 195.0 to $420.0 \mathrm{mbsf}$, hence 34.3 per meter on average.

\section{Results}

\section{Fracture Porosity Estimates}

FMS (Fig. 7) and DLL (Fig. 4) fracture porosity estimates are generally in good agreement, particularly in terms of quantitative evaluation. Computed hydraulic apertures are as high as $0.6 \mathrm{~mm}$ in the pillows and as low as $30 \mu \mathrm{m}$ in the flows. The two vertical structures detected by the DLL at 310.0 and $325.0 \mathrm{mbsf}$ are also described in FMS data as mostly subvertical, whereas that located between 375.0 and $385.0 \mathrm{mbsf}$ is somewhat subdued in DLL record. Although the total FMS estimate gives greater values here than DLL estimates, it should be remembered that the DLL provides only a minimum estimate of fracture porosity, as opposite sets might "cancel out" in terms of electrical response. This artifact is particularly visible from 350.0 to $400.0 \mathrm{mbsf}$, where FMS-derived porosities are high for both subhorizontal and subvertical sets and, whereas the DLL shows a strong competition between the two sets, it systematically excludes the weaker one. A similar behavior is obtained from 240.0 to $275.0 \mathrm{mbsf}$, where opposite sets are also conflicting.

\section{Fractures and Alteration}

Each peak in natural radioactivity (GR), expected to be related to potassium concentration in relation with basalt alteration resulting from hydrothermal circulation, is found to correspond to a peak in "total" fracture porosity from FMS and a trough in electrical resistivity from the DLL, except somewhat for the larger one located at 397.0 mbsf (Fig. 7). These fractures are conduits along which fluids have permeated to react with the basalt.

\section{Active Fault Zone}

The lowest electrical resistivity value recorded in the hole with the DLL is found at $356.0 \mathrm{mbsf}$. Below, a high degree of fracturing is obtained, with lower values in the flows and higher values in the pillows. The hole is also relatively cylindrical below this depth. Above, the hole is generally of elliptical shape throughout, although of small ellipticity degree, as if a change in stress field conditions occurred at 356.0 mbsf. This depth is also a local maximum in fracturing intensity in both DLL- and FMS-derived porosity estimates. As a consequence, these evidences suggest the presence of a presently active fault at $356.0 \mathrm{mbsf}$.

When detailed and presented in terms of azimuth instead of dip (Fig. 8), the "tadpole" plot reveals also an abrupt rotation in conjugated sets of vertical (blue), and "intermediate" (green) sets exactly at that depth, with a $145^{\circ} \mathrm{N}$ mean strike direction above, and $005^{\circ} \mathrm{N}$ below. This abrupt rotation is the only one detected in the lower part of the hole, where continuous and slow rotations with depth are other-
A

DLL-derived porosity (\%)

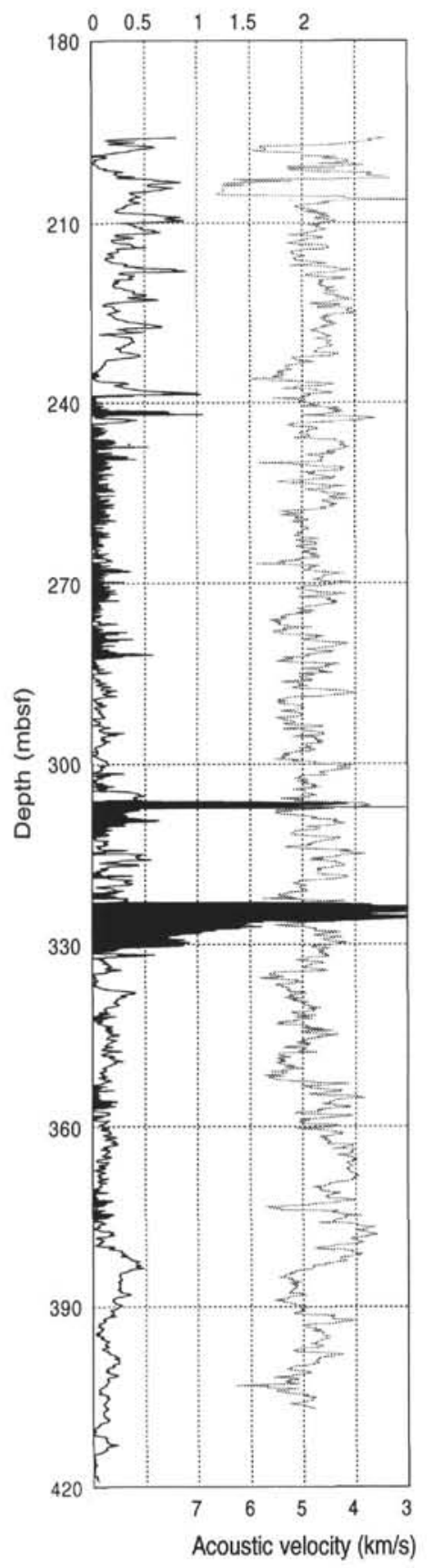

B

Porosity (\%)

$0 \quad 612182430$

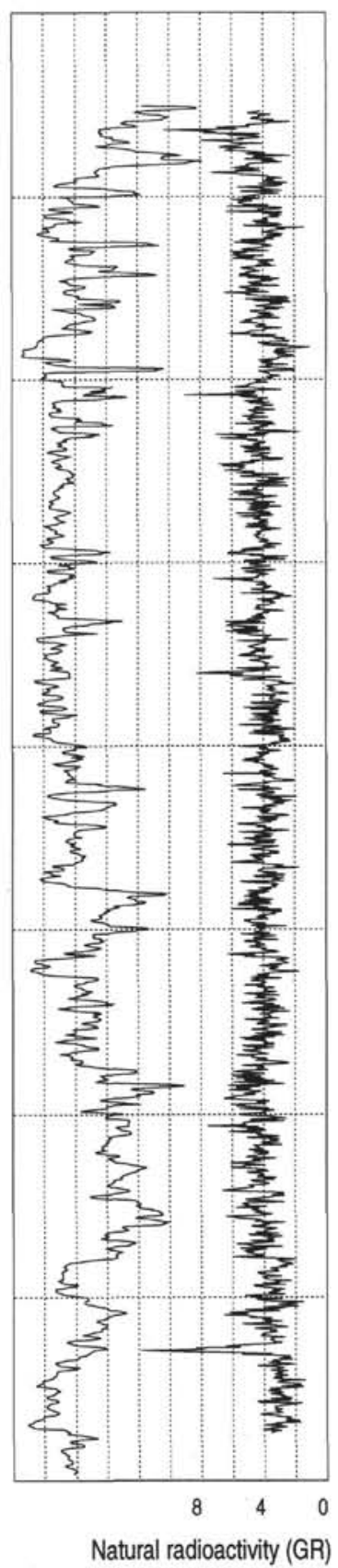

Figure 4. A. Acoustic velocity and porosity estimates from DLL in Hole $896 \mathrm{~A}$ are presented vs. depth. Black peaks indicate the dominating presence of vertical conductive features in terms of volume (porosity), and white peaks indicate horizontal ones. B. Total porosity derived from electrical resistivity from Archie's formula and natural radioactivity (GR) are presented vs. depth. 


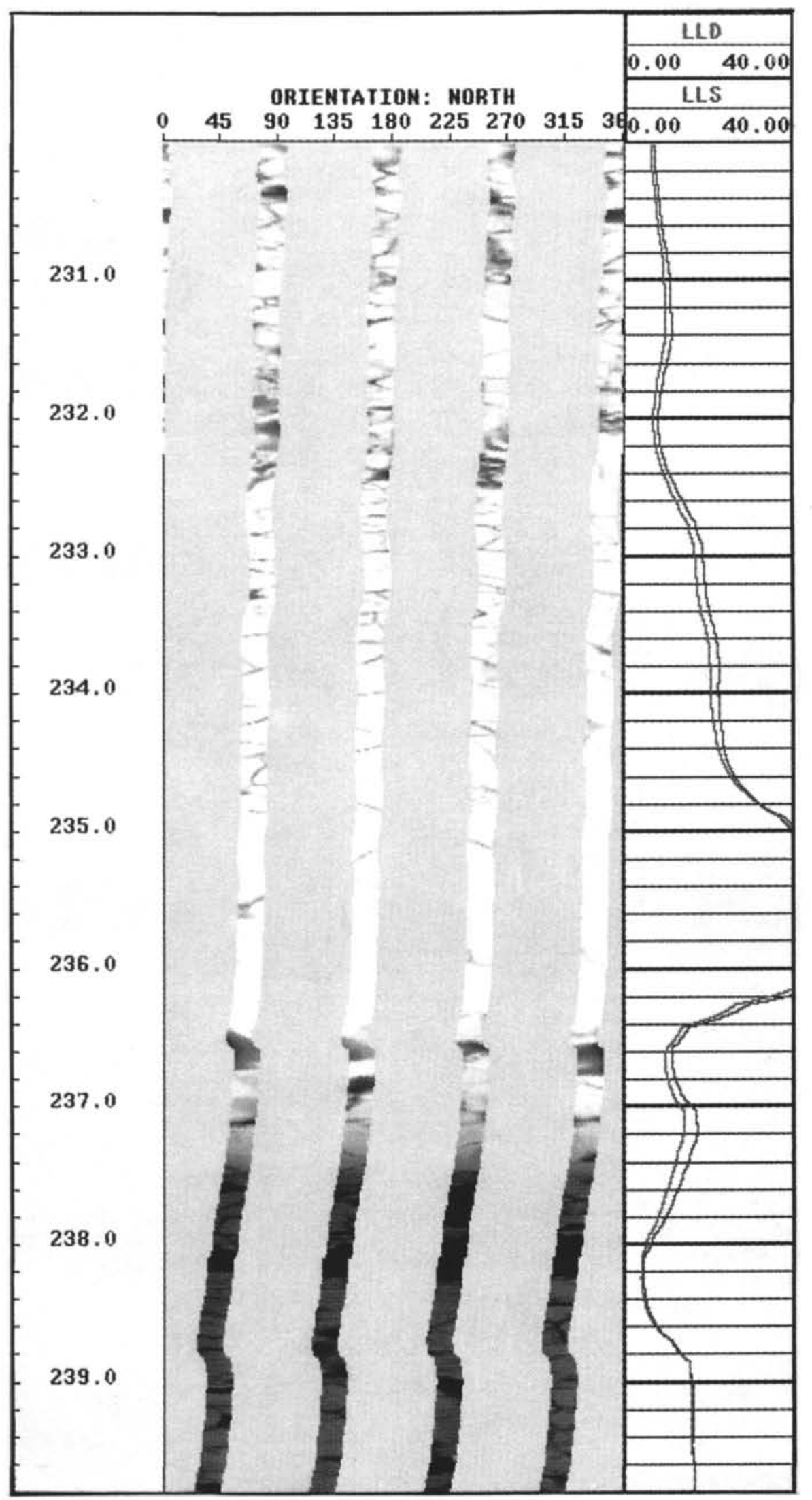

Figure 5. Azimuthal FMS image of the base of a resistive unit considered as a thin flow (down to $236.5 \mathrm{~m}$ ) and the underlying more conductive pillow basalts. To the right, meter-scale electrical resistivity curves from DLL $(\Omega \mathrm{m})$ emphasize the base of the resistive flow and a series of conductive features at $238.0 \mathrm{mbsf}$. The difference in vertical resolutions of the two data sets is of two orders of magnitude. 


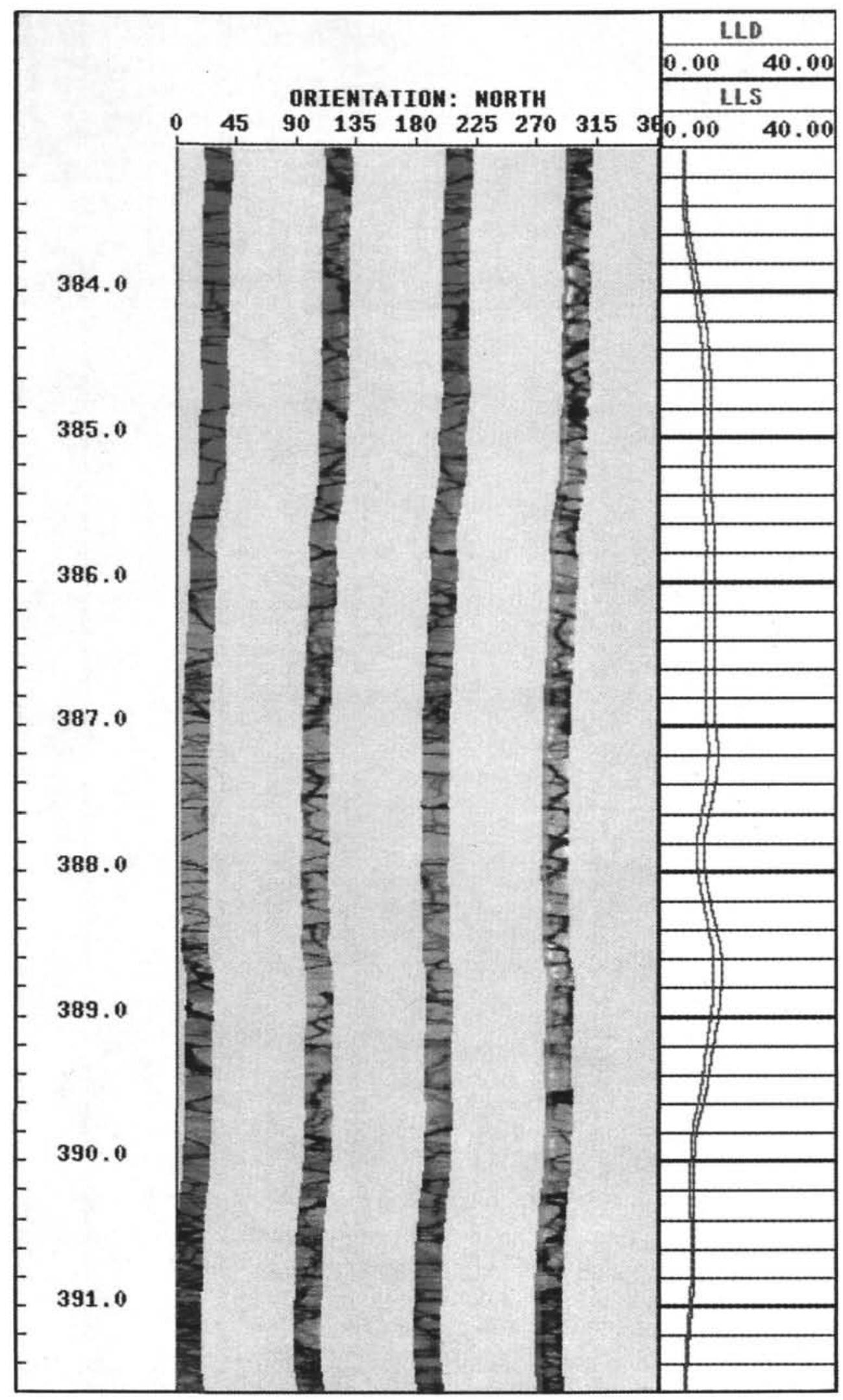

Figure 6. Azimuthal FMS image of pillow basalts. Darker levels are contacts between pillows, and most thin conductive events are shallow dipping fractures. Some steeper fractures are visible throughout, with near-vertical events at the bottom of the section on the east pointing image. Electrical resistivity is to the right $(\Omega \mathrm{m})$. 


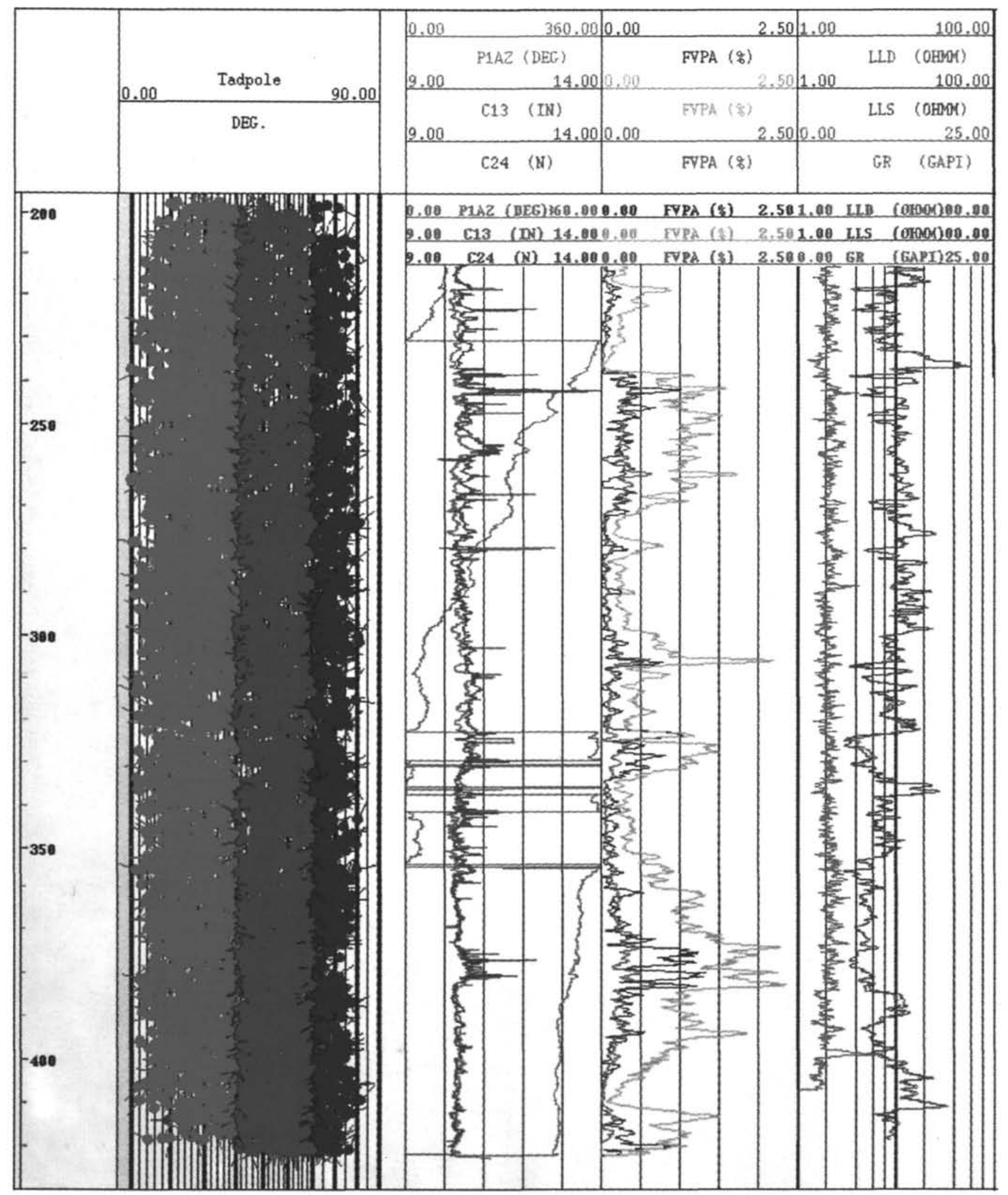

Figure 7. Summary of results from FMS image analysis with FracView. Besides depth below seafloor to the left, each of the 7700 individual conductive events mapped in Hole 896A is represented as "tadpoles" in terms of dip angle and azimuth, with horizontal (red), "intermediate" (green), and vertical (blue) sets defined for the purpose of the analysis. Orientation of the FMS sonde in the hole with respect to true north (P1AZ) shows the rotation of the tool in the hole during recording, and orthogonal calipers ( $\mathrm{C} 13$ and $\mathrm{C} 24)$ are plotted directly to the right of the "tadpole" plot. In the middle track, horizontal (red), vertical (blue) and total fracture porosity profiles (yellow) are reported, from $0 \%$ to $2.5 \%$. The right-hand track with DLL electrical resistivity and natural radioactivity (GR) is presented as lithostratigraphic reference. 


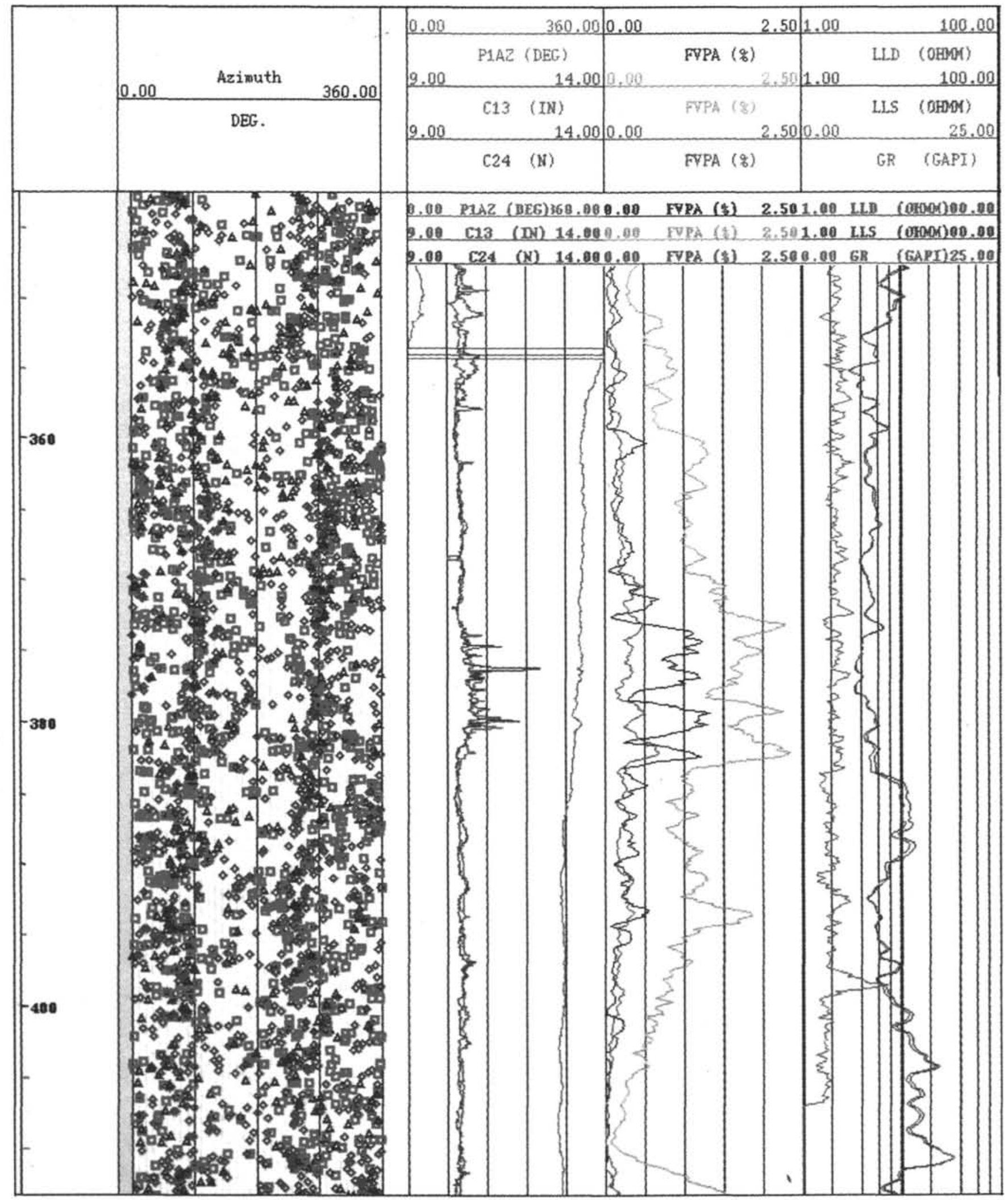

Figure 8. Results of FMS image analysis: same as Figure 7 over a shorter interval (from 340.0 to 420.0 mbsf) and with detected planes presented vs. azimuth, not dip. 
wise observed. The change in borehole enlargements behavior at the proposed fault depth is also extremely clear at this scale (Fig. 8).

\section{Azimuth and Dip of FMS Fractures}

The 7721 traces obtained from FMS images have been plotted in terms of plunge directions and strike trends (Fig. 9) with rose diagrams, following the same classification into horizontal $\left(0^{\circ}-30^{\circ}\right)$, "intermediate" $\left(30^{\circ}-60^{\circ}\right)$, and vertical $\left(60^{\circ}-90^{\circ}\right)$ sets. In terms of plunge directions, steep fractures dip in conjugated sets toward $065^{\circ}$ and $\mathrm{N} 245^{\circ}$, on average, whereas horizontal ones globally plunge in the northern quadrants, suggesting a slight basement tilt toward the ridge axis. The magnitude of this tilt has not been determined at this stage of the analysis. The "intermediate" set appears to combine both characters. Strike directions show as expected a fairly even distribution for subhorizontal features, except for a slight peak toward $165^{\circ} \mathrm{N}$. This direction is also that of mean strike for the "intermediate" and entire data sets, whereas the subvertical one appears to provide two main directions pointing $145^{\circ} \mathrm{N}$ and $175^{\circ} \mathrm{N}$.

\section{Borehole Elongation and Stress}

The hole size measured by the FMS shows that the borehole was maintained in excellent shape, with values ranging mostly from 10.2 to $11.2 \mathrm{in}$. The presence of an elliptical borehole shape is traditionally interpreted in terms of breakouts (Bell and Gough, 1979), with the long axis of the borehole pointing toward the minimum horizontal stress direction. From the analysis of BHTV acoustic images in Hole 504B, Morin et al. (1990) derived a main mode of ellipticity pointing $114^{\circ} \mathrm{N}$. This direction was proposed to represent the local minimum horizontal stress direction. A second, less important, but exactly orthogonal mode of enlargement was also found. This second mode was attributed to thermal fracturing related to the cooling of the hole with cold seawater, and found again at the base of the sheeted dikes complex during Leg 148 (Ayadi et al., this volume).

In Hole 896A, the same modes of borehole elongations are outlined (Fig. 9), with a main mode centered on $125^{\circ} \mathrm{N}$ and in spite of the very small degree of ellipticity encountered (Fig. 7). The threshold for significant elongation detection was chosen as 0.22 in., lower values giving an erratic data set. Borehole long axis rotations up to $60^{\circ}$ are observed over 10 -m-long intervals above fault zones detected from DLL measurements (Fig. 10). In particular, significant rotations are found at 245.0, 275.0,305.0, 325.0, and $355.0 \mathrm{mbsf}$, where the presence of a fault trace was inferred from standard logs and FMS image analysis.

\section{Basement Structure}

In an attempt to relate meter- and centimeter-scale structural features detected from standard downhole measurements and borehole wall images, respectively, a composite plate treating subhorizontal, "intermediate", and subvertical fracturing from FMS separately along with DLL-derived porosity profiles was assembled (Fig. 11). Subhorizontal events are characterized by the absence of south-dipping planes, as seen earlier. North-dipping planes are absent near 355.0 and $385.0 \mathrm{mbsf}$, where subvertical structures are inferred. The relative density of generally west-dipping events seems to be larger above 325.0 mbsf.

Fracturing "intermediate" dips appear to be more intense at the bottom of the hole, whereas rotations of conjugated sets of fractures appear to follow the tool motion into the hole. Whether we face a sampling bias, or whether hole direction and fractures that preferentially reopened-and hence were detected from FMS images-are being affected by the stress field remains to be resolved at this point. Subvertical planes are less numerous and have an attitude similar to that of "intermediate" planes.
The next step in describing in a detailed fashion the structure of the upper crust at Site 896 consists of zoning the analysis vs. depth. A first attempt at such a detailed description is given in Figure 12, where strike directions of vertical are presented for eight different sections selected from DLL-derived fracture porosity profiles as follows: (A) (190.0-240.0 mbsf), with 164 planes (3.3 per meter); (B) (240.0-285.0 mbsf), with 243 planes (5.4 per meter); (C) (285.0305.0 mbsf), with 135 planes (4.5 per meter); (D) (305.0-320.0 mbsf), with 84 planes (5.6 per meter); (E) (320.0-335.0 mbsf), with 93 planes (6.2 per meter); (F) (335.0-355.0 mbsf), with 136 planes (6.8 per meter); (G) (355.0-385.0 mbsf), with 155 planes (5.2 per meter); and (H) (385.0-420.0 mbsf), with 267 planes (7.6 per meter). The investigation of these data has been stopped at this point because of lack of time considering the present publication deadline. Further analyses should follow shortly.

Strike data sets are generally well organized in azimuth, either unimodal as in C, G and H, or bimodal as in A, B, D, E and F. The main strike mode varies widely over this short 240 -m-long interval, and a more complete understanding of the structure of the penetrated section should arise in the near future from the detailed analysis of this data set.

\section{CONCLUSION}

The detailed analysis of downhole measurements and FMS images recorded in Hole 896A has yielded a very precise description of the fractured upper oceanic basement. Extremely low resistivity values and consistently high acoustic velocities throughout indicate that the basement has been altered to a large extent at this topographic high and heat-flow maximum, but also that cracks and fractures once conveying fluid to alter fresh basalts are now sealed. Nearly 7700 features mapped over $225 \mathrm{~m}$ of images have been mapped from FMS images. A comprehensive structural description of the penetrated section should arise from the present data set in the near future.

\section{ACKNOWLEDGMENTS}

We thank Robin Newmark for a detailed and constructive review of the manuscript, as well as Schlumberger-Paris for making available the FMS processing and analysis software at academic rates. This work was supported by the "Marine Geosciences" ODP support program of CNRS, France.

\section{REFERENCES}

Alt, J.C., Kinoshita, H., Stokking, L.B., et al., 1993. Proc. ODP, Init. Repts., 148: College Station, TX (Ocean Drilling Program).

Archie, G.E., 1942. The electrical resistivity log as an aid in determining some reservoir characteristics. J. Pet. Tech., 5:1-8.

Becker, K., 1985. Large-scale electrical resistivity and bulk porosity of the oceanic crust, Deep Sea Drilling Project Hole 504B, Costa Rica Rift. In Anderson, R.N., Honnorez, J., Becker, K., et al., Init. Repts. DSDP, 83: Washington (U.S. Govt. Printing Office), 419-427.

Bell, J.S., and Gough, D.I., 1979. Northeast-southwest compressive stress in Alberta: evidence from oil wells. Earth Planet. Sci. Lett., 45:475-482.

Brace, W.F., Orange, A.S., and Madden, T.R., 1965. The effect of pressure on the electrical resistivity of water-saturated crystalline rocks. J. Geophys. Res., 70:5669-5678.

Ellis, D.V., 1987. Well Logging For Earth Scientists: New York (Elsevier).

Hey, R., Johnson, G.L., and Lowrie, A., 1977. Recent plate motions in the Galapagos area. Geol. Soc. Am. Bull., 88:1385-1403.

Langseth, M.G., Mottl, M.J., Hobart, M.A., and Fisher, A., 1988. The distribution of geothermal and geochemical gradients near Site 501/504: implications for hydrothermal circulation in the oceanic crust. In Becker, K., Sakai, H., et al., Proc. ODP, Init. Repts., 111: College Station, TX (Ocean Drilling Program), 23-32. 
Lüthi, S.M., and Banavar, J.R., 1988. Application of borehole images to three-dimensional geometric modeling of eolian sandstone reservoirs, Permian Rotliegende, North Sea. AAPG Bull., 72:1074-1089.

Lüthi, S.M., and Souhaité, P., 1990. A method for fracture extraction and width determination from electrical borehole scans. Geophysics, 55:821833.

Moos, D.M., Pezard, P.A., and Lovell, M., 1990. Elastic wave velocities within oceanic layer 2 from sonic full waveform logs in Deep Sea Drilling Project Holes 395A, 418A, and 504B. J. Geophys. Res., 95:91899207.

Morin, R.H., Newmark, R.L., Barton, C.A., and Anderson, R.N., 1990. State of lithospheric stress and borehole stability at Deep Sea Drilling Project Site 504B, eastern Equatorial Pacific. J. Geophys. Res., 95:9293-9303.

Newmark, R.L., Anderson, R.N., Moos, D., and Zoback, M.D., 1985. Sonic and ultrasonic logging of Hole 504B and its implications for the structure, porosity, and stress regime of the upper $1 \mathrm{~km}$ of the oceanic crust. In
Anderson, R.N., Honnorez, J., Becker, K., et al., Init. Repts. DSDP, 83: Washington (U.S. Govt. Printing Office), 479-510.

Pezard, P.A., 1990. Electrical properties of mid-ocean ridge basalt and implications for the structure of the upper oceanic crust in Hole 504B. J. Geophys. Res., 95:9237-9264.

Pezard, P.A., and Anderson, R.N., 1990. Electrical resistivity, anisotropy, and tectonic context. Trans. SPWLA, Paper M, 31st Annu. Log. Symp., Lafayette, LA, USA.

Pezard, P.A., Lovell, M., and Ocean Drilling Program Leg 126 Shipboard Scientific Party, 1990. Downhole images: electrical scanning reveals the nature of subsurface oceanic crust. Eos, 71:710.

Date of initial receipt: 22 August 1994

Date of acceptance: 22 February 1995

Ms 148SR-153 

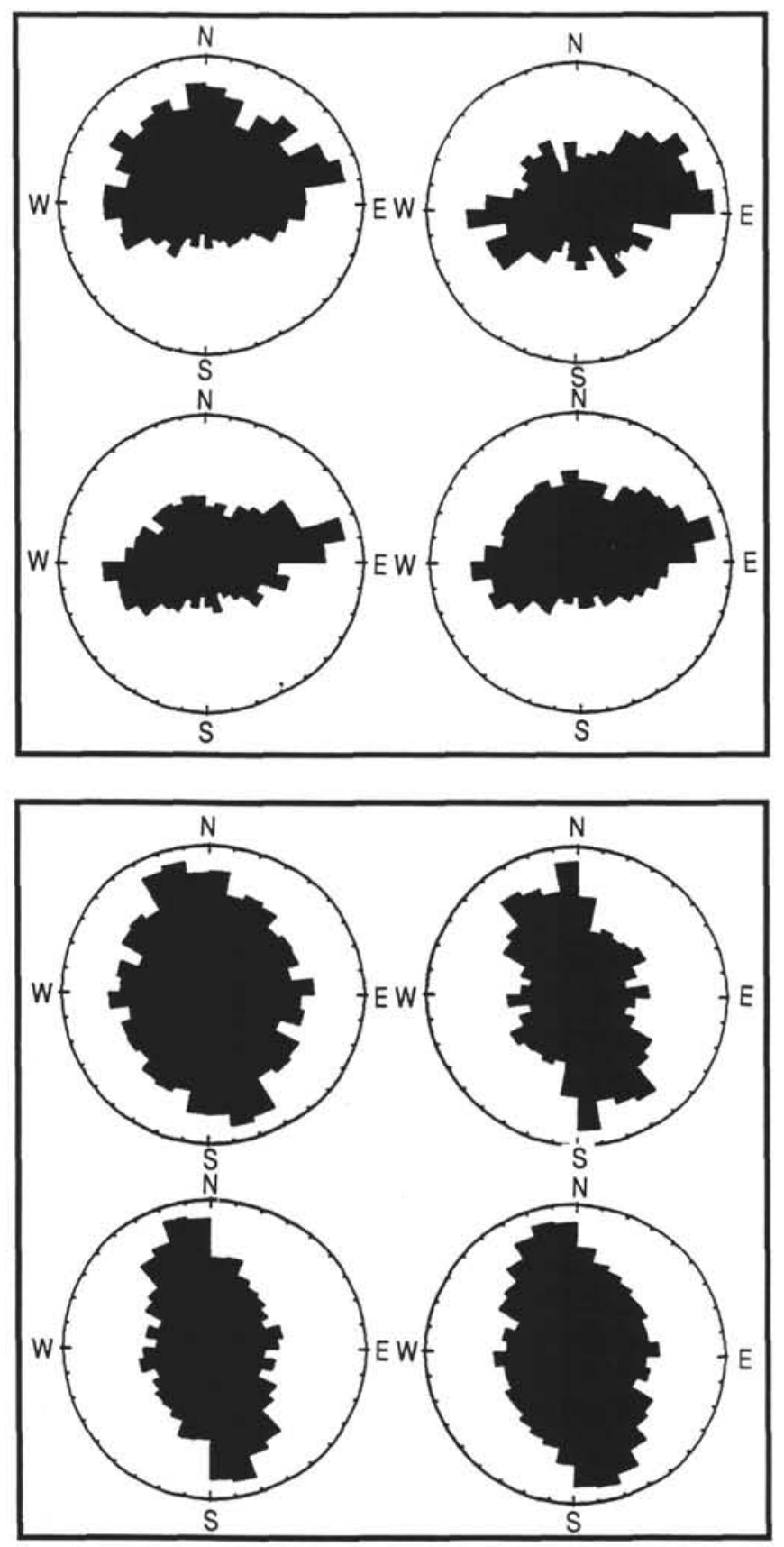

Figure 9. Top half of figure: Rose diagrams of azimuth (plunge) directions for planes derived from FMS image analysis in Hole 896A. Upper left: subhorizontal planes (3295 samples); lower left: "intermediate" planes (3165 samples); upper right: subvertical planes (1265 samples); lower right: all planes ( 7725 samples). Bottom half of figure: Rose diagrams of strikes distributed as for plunge directions above.

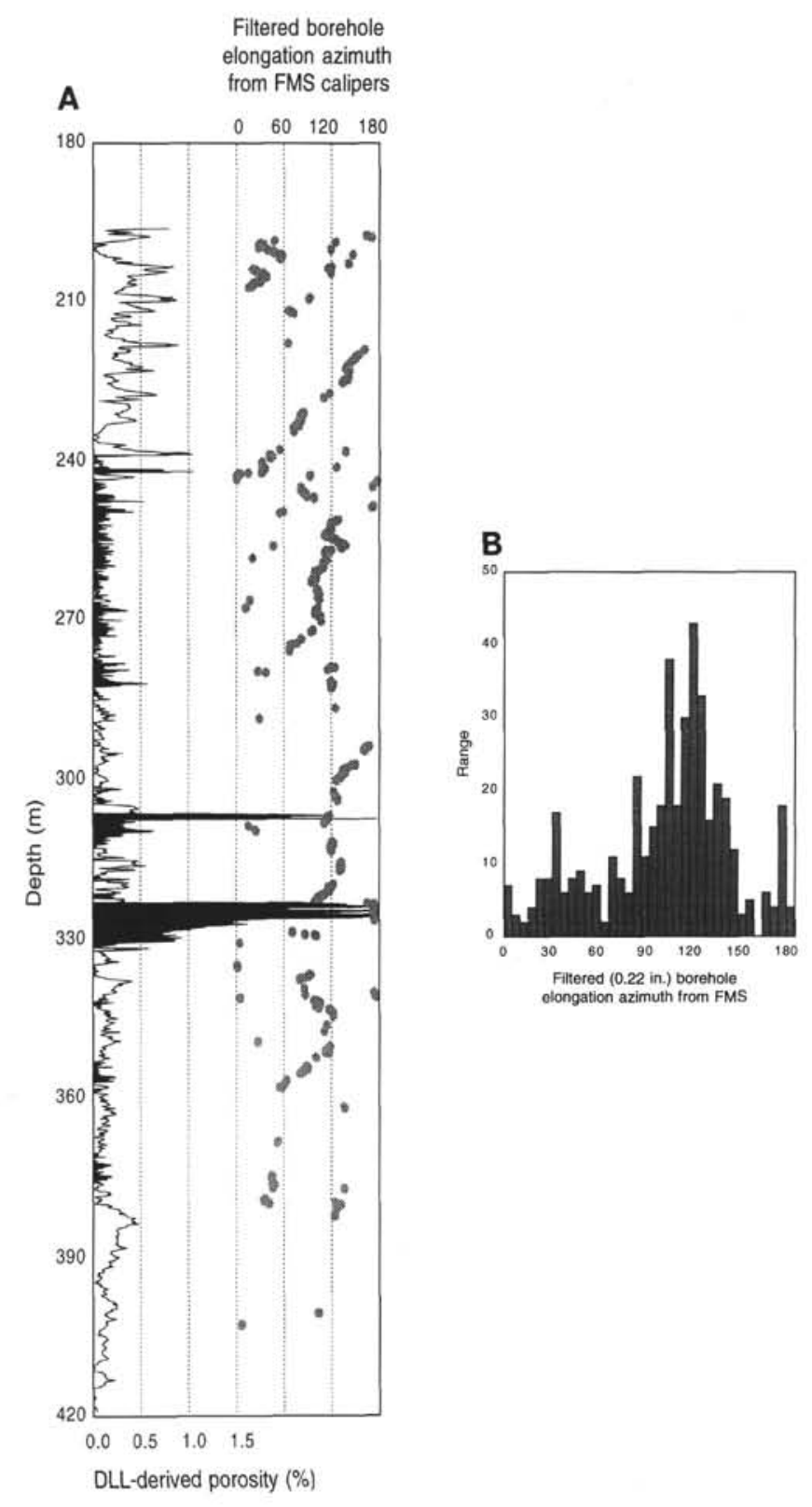

Figure 10. A. DLL-derived porosity estimates presented along azimuths of borehole elongations for caliper differences greater than 0.22 in. B. Histogram of filtered borehole elongation azimuth from FMS. 


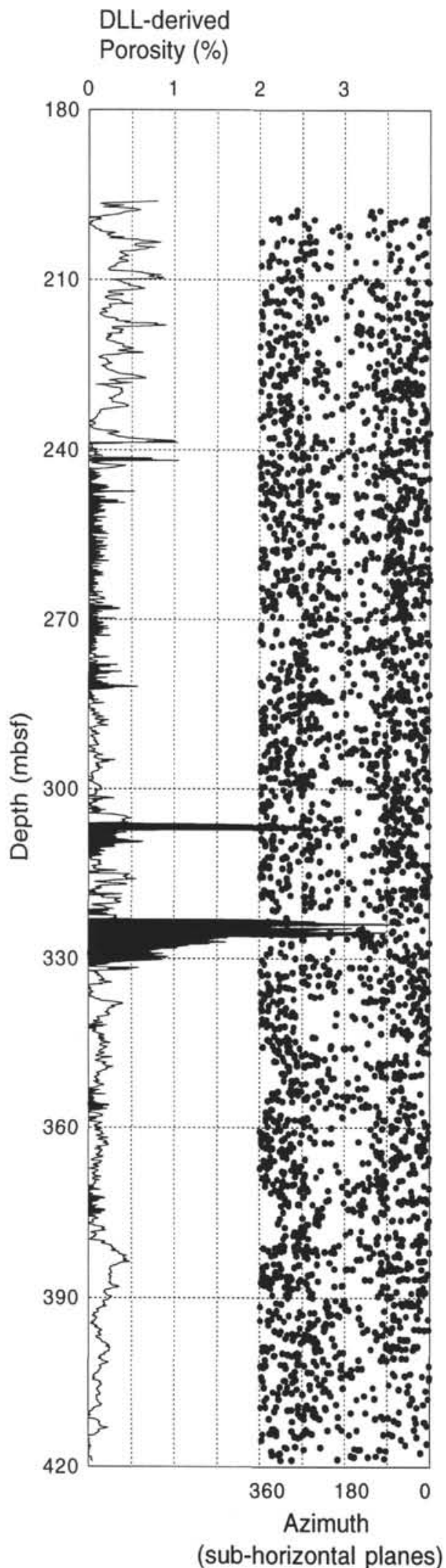

DLL-derived

Porosity (\%)

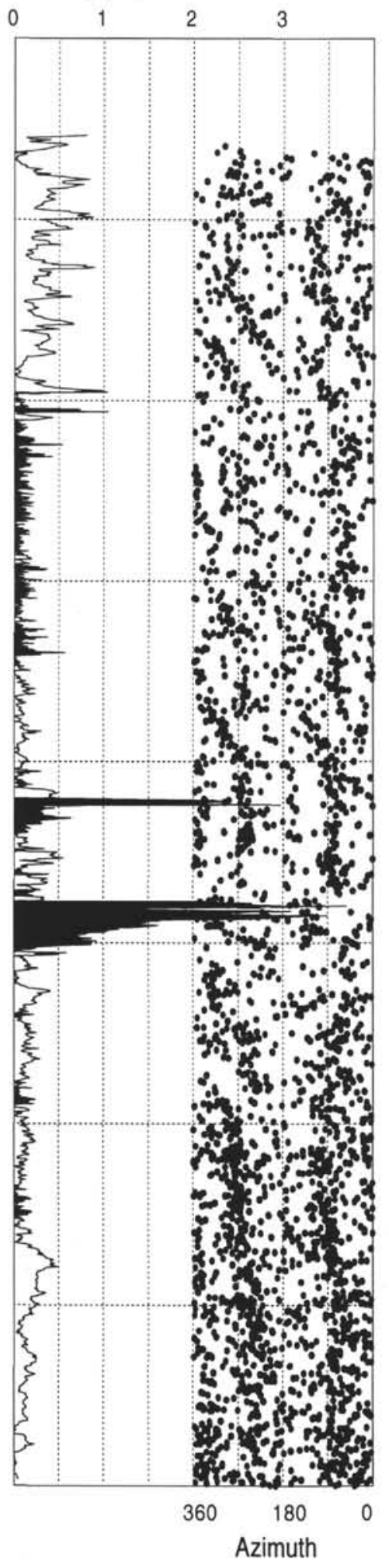

(intermediate planes)

\section{DLL-derived}

Porosity (\%)

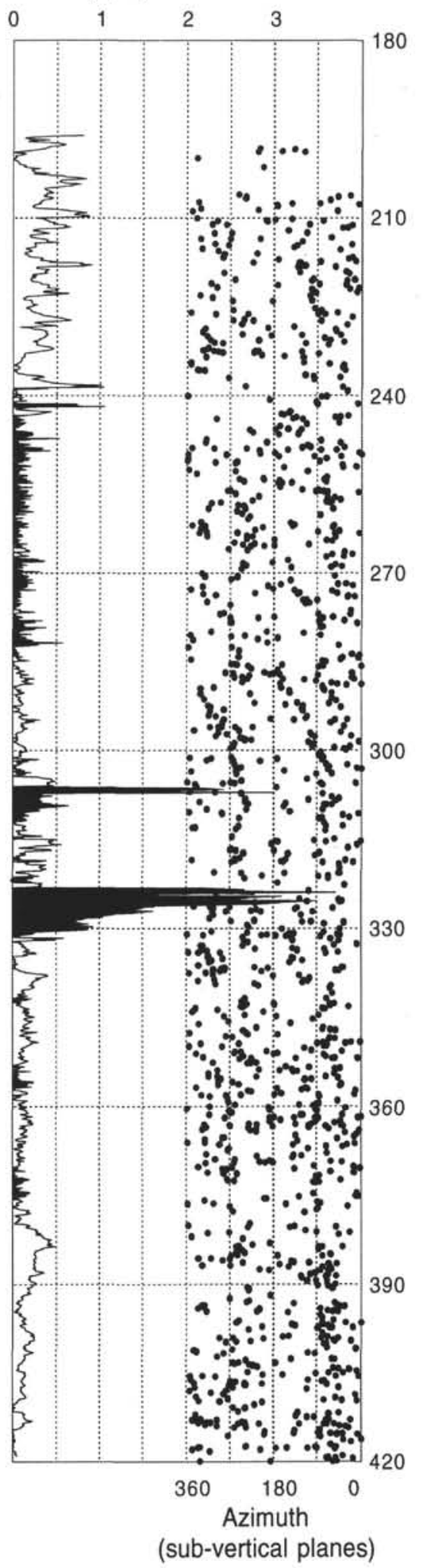

Figure 11. DLL-derived porosity estimates presented along azimuths of subhorizontal, "intermediate," and subvertical planes (from left to right) derived from FMS image analysis. The vertical fracture porosity from DLL is in black. 


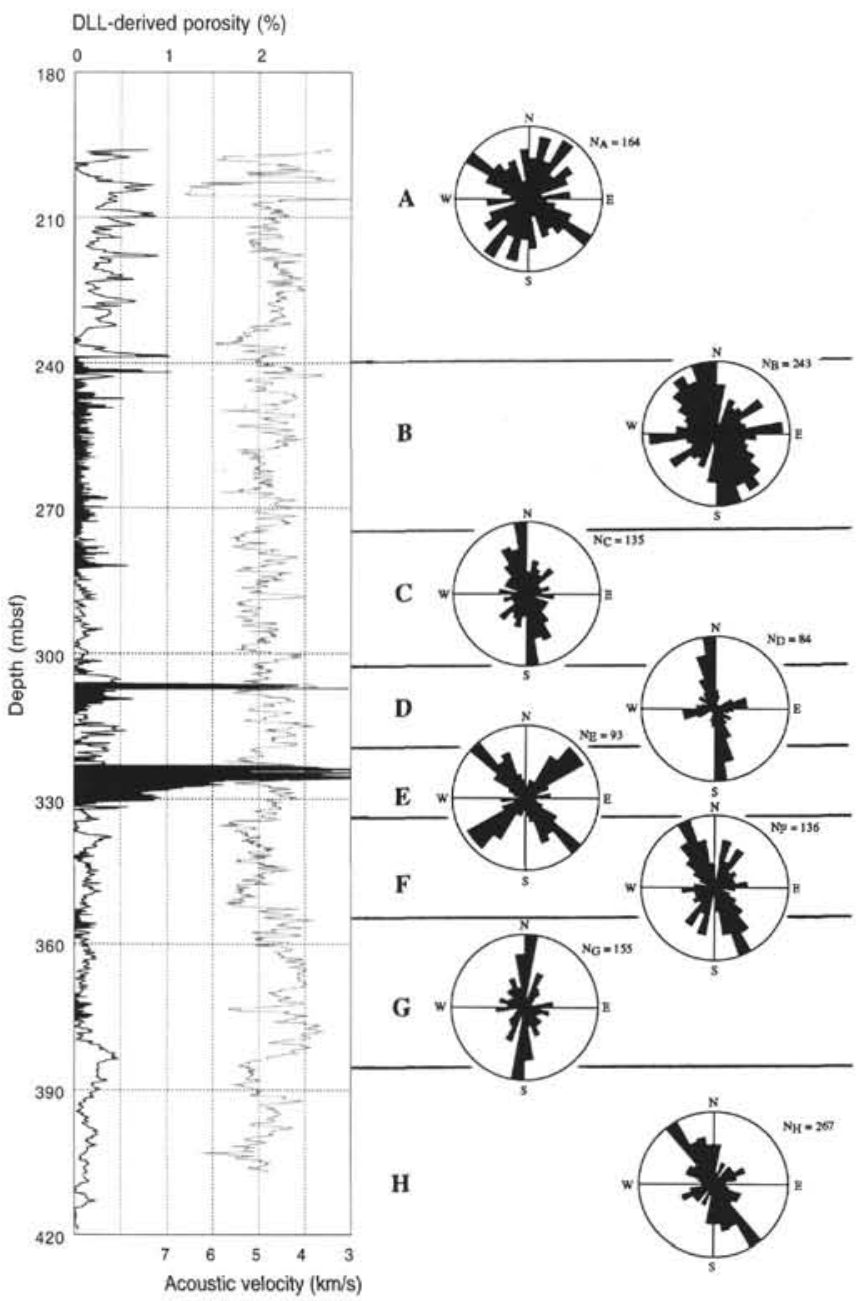

Figure 12. At left, same as in Figure 4. At right, rose diagrams of subvertical features strike directions of eight zones defined on the basis of the DLLderived porosity curve character. A. (190.0-240.0 mbsf), with 164 planes (3.3 per meter). B. (240.0-285.0 mbsf), with 243 planes ( 5.4 per meter). C. (285.0-305.0 mbsf), with 135 planes ( 4.5 per meter). D. (305.0-320.0 mbsf), with 84 planes ( 5.6 per meter). E. (320.0-335.0 mbsf), with 93 planes $(6.2$ per meter). F. (335.0-355.0 mbsf), with 136 planes (6.8 per meter). G. (355.0-385.0 mbsf), with 155 planes (5.2 per meter). H. (385.0-420.0 mbsf); with 267 planes ( 7.6 per meter). 